\title{
Exclamations and their discourse effects in Japanese
}

\author{
Hitomi Hirayama*
}

\begin{abstract}
This paper discusses two kinds of sentences with nante that can express exclamations in Japanese. I show that these two nante exclamations show the contrast observed between sentence exclamations and wh-exclamatives in English (Rett 2011). Based on the data, I propose that nante in the two types of sentences can be analyzed in a unified way: nante is like what in English in that it can range over a variety of categories. The semantic composition shows that the two nante sentences have different sentence types and hence different discourse effects (Farkas \& Roelofsen 2017). One type is a marked assertion, and the other is a bonafide exclamative. I show the contrast using the discourse model in Farkas \& Bruce (2010): The exclamative updates the speaker's commitment, not the potential future common ground.
\end{abstract}

Keywords. exclamatives; discourse effects; Japanese

1. Introduction. Natural languages provide us with multiple ways to achieve the same goal: To ask whether it is raining, for example, one can use a polar question ('Is it raining?'), a tag question ('It's raining, isn't it?'), or a high negation polar question ('Isn't it raining?'). The goal of these questions is the same, but the speaker can convey accompanying contextual information (e.g., whether they think it is likely to be raining) by using different kinds of questions strategically.

However, this is not a unique feature of the interrogatives. English has various ways of conveying the speaker's surprise, as does Japanese. This paper investigates the discourse effects of two kinds of exclamations in Japanese that share the same expression nante. While they both convey the speaker's surprise, they are based on different speaker's expectations and behave differently toward challenge by the addressee using no. To explain these differences, this paper argues that one is a bonafide exclamative, while the other is a special assertion. The rest of the paper is structured as follows: In Section 2, exclamations with nante are shown and compared with English exclamatives and sentence exclamations. Section 3 provides an analysis of the two nante exclamations from the semantic and pragmatic perspectives. Section 4 presents the conclusions and outlines possible future directions.

2. Data. This paper focuses on two types of sentences in (1) that can express the speaker's surprise. These sentences share the same expression, nante, even though it appears in different places in a sentence. ${ }^{1}$ In one type, nante appears at the very end of the sentence, as in (1a), while in the other nante precedes adjectives, nouns, or adverbs, as in (1b). In each case, the

* This research is supported by Grant-in-Aid for Research Activity Start-up by Japan Society for the Promotion of Science(JSPS) (Grant Number: JP19K23044). Author: Hitomi Hirayama, Kyushu Institute of Technology (hirayama@dhs.kyutech.ac.jp)

${ }^{1}$ This paper proposes the unified analysis of nante in the two types of exclamations in (1a). However, the two nante have different etymology. The one in (1a) was originally the combination of nado 'things like' and to, which is a quotation marker. The other comes from a wh-word nantoiu 'how'. Despite the differences in etymology, they seem to share a basic semantic aspect. How they have been reduced to the function of conveying surprise is another question to be pursued in future research. 
speaker's surprise is conveyed by uttering the sentence. ${ }^{2}$
a. Taro-ga oisii dezaato-o tukuru nante!
T-NOM delicious dessert-ACC make NANTE
'Wow, Taro makes delicious desserts!'
b. Taro-wa nante oisii dezaato-o tukuru no-daroo!
T-TOP NANTE delicious dessert-ACC make FOC-MOOD
'What delicious desserts Taro makes!'

As the English translation of (1) shows, the differences between the two types of exclamations in Japanese are analogous to those between sentence exclamations and wh-exclamatives in English. This paper focuses on two similarities, namely, their scalarity and the behavior to the response particle.

2.1. SCAlarity. Rett (2011) pointed out that sentence exclamations and $w h$-exclamatives in English differ in that the former allows non-scalar expectations while the latter does not, showing the contrast between (2) and (3) below:

(2) Sentence Exclamation: Non-scalar

A: (Wow,) John bakes delicious desserts! (Expectation: John doesn't bake.)

a. $\checkmark$ A: I would have guessed John to be a terrible pâtissier!

b. \# A: I guessed he'd make delicious desserts, but these are beyond my expectation!

(3) Wh-exclamative: Scalar

A: (My,) What delicious desserts John bakes!

(Expectation: John's dessert has some degree of deliciousness)

a. $\checkmark$ A: I would have guessed John to be a terrible pâtissier!

b. $\checkmark$ A: I guessed he'd make delicious desserts, but these are beyond my expectation!

Looking at the case with a sentence exclamation: (2), the continuation where the speaker explicitly states that they expected that John would bake delicious desserts is infelicitous, which is not the case when a wh-exclamative is used. The difference comes from the fact that the sentence exclamation targets a non-scalar component as the speaker's expectation.

Two nante exclamations in Japanese show a similar contrast. The following two sentences state a non-scalar expectation and a scalar expectation, respectively.

a. Taro-wa dezaato-o tukuru-no-wa heta-da to omotteita.

Taro-TOP dessert-ACC make-NL-TOP poor-COP COMP thought

'I thought Taro was poor at making desserts.'

b. Taro-wa oisii dezaato-o tukuru-to omotteita kedo kore-wa kitai

Taro-TOP delicious dessert-ACC make-COMP thought but this-TOP expectation izyoo da

more than COP

'I thought Taro would make delicious desserts but this is beyond my expectation.'

After the utterance with the sentence-final nante (1a), only (4a) is a possible continuation, while the exclamation with the intra-sentential nante $(1 \mathrm{~b})$ is compatible with both continua-

${ }^{2}$ The following abbreviations are used in the glosses: $\mathrm{ACC}=$ accusative, $\mathrm{COMP}=$ complementizer, $\mathrm{COP}=$ copula, FOC $=$ focus marker, MOOD $=$ mood marker, $\mathrm{NL}=$ nominalizer, $\mathrm{NOM}=$ nominative, $\mathrm{TOP}=$ topic marker 
tions in (4). In other words, exclamation with the sentence-final nante is non-scalar, whereas that with the intra-sentential nante is scalar.

2.2. BEHAVIOR TOWARD RESPONSE PARTICLES. In English, wh-exclamatives cannot be challenged by using $n o$, as shown in $(5 \mathrm{~b}){ }^{3}$ In contrast, the sentence exclamation can be challenged by $n o$, as in (5a).

(5) a. Sentence Exclamation: No can be used to challenge the speaker

A: (Wow,) John bakes delicious desserts!

$\checkmark$ B: No, these are store-bought.

b. Wh-exclamative: No can be used to challenge the speaker

A: (Wow,) What delicious desserts John bakes!

??B: No, these are store-bought.

It is possible to observe a similar contrast in Japanese. (6) is a challenge by the addressee accompanying iya 'no'.

(6) Iya, sore-wa mise-de katta yatu

no it-COP store-at bought things

'No, they are store-bought.'

(6) can follow (1a), which accompanies the sentence-final nante. The acceptability declines when (6) follows (1b). As in English, the challenge to a wh-exclamative by the addressee is possible without iya 'no'. To the author, to the wh-exclamative, (6) without iya sounds natural with a little pause or a filler such as etto 'well', which presumably shows some hesitation and lowers the aggressiveness of the challenging tone.

Summarizing the contrasts we have observed, we can obtain the following results shown in Table 1: Overall, exclamation with the sentence-final nante behaves like a sentence excla-

\begin{tabular}{|l|c|c|}
\hline & Scalarity & Challengeable by no \\
\hline (1a): Sentence-final nante & $\boldsymbol{X}$ & $\checkmark$ \\
\hline (1b): Intra-sentential nante & $\checkmark$ & $\boldsymbol{X}$ \\
\hline
\end{tabular}

Table 1. Properties of exclamations in Japanese

mation in English. In contrast, intra-sentential nante is similar to $w h$-exclamatives. The next step is to provide an analysis that accounts for the difference summarized in Table 1, keeping in mind that both share the same expression, nante.

3. Analysis. This section aims to account for the differences between the two kinds of exclamations in Japanese by arguing that they end up with different semantics and pragmatic effects (discourse effects), even though the base of the semantic denotation of nante is shared.

3.1. Semantics. The two kinds of exclamations share the expression nante. It is possible to provide a unified account of the semantics of nante by setting its range underspecified, as in (7). This approach is also adopted by Rett (2011).

${ }^{3}$ As discussed in Chernilovskaya et al. (2012), this does not mean that $w h$-exclamatives cannot be challenged by the addressee at all. The infelicity of no can be explained by the assumption that no shows the response to what is put on the Table in the discourse model. See the discussion in Section 3.2. 
$\llbracket$ nante $\rrbracket \rightsquigarrow \lambda P_{\langle\tau, t\rangle} \lambda x_{\tau} . P(x)$, where $\tau$ is any semantic type

The differences between the two nantes arise from the different ranges of the function in (7). When it appears intra-sententially, the range is set as degrees. In contrast, the range over which sentence-final nante goes is the domain of truth values. The difference is illustrated in (8) below.

$$
\begin{array}{ll}
\text { a. } & \text { Intrasentential nante } \\
& \llbracket \text { nante } \rrbracket \rightsquigarrow \lambda P_{\langle d, t\rangle} \lambda x_{d} . P(x)
\end{array}
$$

b. Sentence final nante $\llbracket$ nante $\rrbracket \rightsquigarrow \lambda P_{\langle t, t\rangle} \lambda x_{t} . P(x)$

These denotations of nante are used in computing the semantic denotation of these two exclamations along with other operators.

3.1.1. Exclamations with the intra-Sentential nante. The syntactic aspects of this exclamation are analyzed in Ono (2006). Following the analysis given there, the semantic analysis given in this section assumes that nante covertly moves to Spec CP, leaving a trace of type $d$ (degree). Consequently, the semantic computation of (1b) is performed as in (9):

$$
\begin{aligned}
& \text { a. After covert movement of nante } \\
& \text { (1b) } \rightsquigarrow \llbracket \text { nante } \rrbracket\left(\lambda d . \exists x \text {.make' }(t, x) \wedge \operatorname{dessert}^{\prime}(x) \wedge \text { delicious' }(x, d)\right) \\
& \text { b. } \quad \text { After } \beta \text {-reduction } \\
& \rightsquigarrow \lambda d . \exists x \cdot \text { make' }^{\prime}(t, x) \wedge \operatorname{dessert}^{\prime}(x) \wedge \operatorname{delicious}^{\prime}(x, d)
\end{aligned}
$$

What can be obtained in the last step of (9) is the degree property, not a proposition. Following Rett (2011), I assume that the unsaturated argument in (9b) is filled by the context, which makes the result a proposition that can be an argument of E-FORCE: (10)

E-FORCE $(p)$, uttered by $\mathrm{s}_{C}$, is appropriate in a context $\mathrm{C}$ if $p$ is salient and true in $\mathrm{w}_{C}$. When appropriate, E-FORCE $(p)$ counts as an expression that $\mathrm{s}_{C}$ had not expected that $p$.

[Rett (2011; 429)]

In the end, (1b) is felicitously uttered in a context where there is a degree $d$ such that the speaker had not expected that the desserts that Taro made would be $d$-delicious. This is the interpretation to be obtained as the semantics of exclamatives.

Note that the range of nante used here is degrees, and accordingly, the final result involves existential quantification over degrees. This reflects the scalarity of this exclamation type, similar to the analysis of $w h$-exclamatives in English.

3.1.2. Exclamations with the SEntence-final nante. In the previous section, the semantic denotation of exclamations with the intra-sentential nante is calculated in the same way as that of wh-exclamatives in English, with the semantics of nante going over the range of degrees and with the help of E-FORCE. The semantics of sentence-final nante, however, arises differently from that of sentence exclamations in English. The crucial difference is that no EFORCE operator is used, and there is a grammaticalized aspect involved.

An examination of nante sentences reveals that nante that appears at the very end of the utterance is grammaticalized so that it conveys that the truth of the sentence radical is surprising to the speaker. The sentence-final nante can be used in the embedded context, as in (11). 
In this case, nante is of type $\langle t t, t t\rangle$, and the first argument it takes is a function of the matrix clause, namely $\lambda p$.the speaker cannot believe $p$.

Taro-ga oisii dezaato-o tukuru nante sinzirarenai!

T-NOM delicious dessert-ACC make NANTE can't believe

'I can't believe Taro makes delicious desserts.'

When nante is used in this way, the matrix clause does not have to convey the speaker's surprise. In fact, nante can be used to convey that the truth of the proposition is made light of or is considered rather trivial, as shown in example (12).

Taro-ga oisii dezaato-o tukuru nante minna sitteiru

T-NOM delicious dessert-ACC make NANTE everyone knows

'Everyone knows Taro makes delicious desserts.'

It is possible to use other complementizers, such as $t o^{4}$ in place of nante. What nante contributes in (11) or (12) is to convey the speaker's attitude toward the truth of the proposition to which it is attached, and that does not have to be surprise. Given that, nante used to bridge the matrix clause and the complement clause should be treated differently from intra-sentential nante.

The nante that appears between a complement clause and a matrix clause requires a different treatment, as discussed above. However, sentence-final nante deserves a unified treatment with intra-sentential nante because the interpretations available with it are limited. For example, when someone utters a sentence with final nante, such as (1a), which is repeated here as (13), the only available interpretation is that the speaker is surprised or impressed by the fact that Taro made delicious desserts. In other words, the interpretation of (11) is available, but it is not possible to obtain the interpretation of (12). As shown in (13b), the interpretation may not be directly connected to the speaker's surprise. In this case, the fact that Taro made delicious desserts is contrary to the speaker's expectation, which is why they cannot tolerate the fact. This is more clearly shown by the unavailability of the interpretation in (13d), where the meaning of natural contradicts the fact that the speaker is trying to convey that their expectation was disappointed.

(13) Taro-ga oisii dezaato-o tukuru nante!

T-NOM delicious dessert-ACC make NANTE

a. $\quad \checkmark$ 'Wow, Taro makes delicious desserts!'

b. $\quad \checkmark$ 'I cannot tolerate Taro making such good desserts!'

c. $\quad \boldsymbol{x}$ 'Everyone knows Taro makes delicious desserts.'

d. $\quad \boldsymbol{X}$ 'It's natural that Taro makes delicious desserts.'

One may analyze (13) as a sentence with elided material. That is, (13) is generated from (11) by deleting the matrix clause, namely sinzirarenai 'I cannot believe.' However, if this were the case, the interpretation of (12) would be one of the possible interpretations of (13), which is not the case. From this observation, it is possible to say that nante that appears at the very end of the sentence is grammaticalized to convey that the fact upsets the speaker's expec-

\footnotetext{
${ }^{4}$ In the case of (11), wa should be added in addition to to. I have no clear idea why this is the case, but it is worth noting that a sentence with to wa is understood as an exclamation as well. How a to wa exclamation differs from nante exclamations and how its semantics/discourse effects can be derived are problems for future research.
} 
tation. This leads to the speaker's surprise.

This grammaticalized aspect of nante can be captured if the underspecified range of nante is set as $t$. In other words, the sentence-final nante has the semantics in (14).

$$
\begin{aligned}
& \text { Sentence final nante } \\
& \llbracket \text { nante } \rrbracket \rightsquigarrow \lambda P_{\langle t, t\rangle} \lambda x_{t} . P(x)
\end{aligned}
$$

The grammaticalized part is the first argument $\lambda P_{\langle t, t\rangle}$. It is saturated with a function such as $\lambda p$.surprising $(p)$. After the first argument is saturated, nante takes the sentence radical. The final result is a simple proposition that conveys that $p$ is different from what the speaker expected. Here, there is no need to use E-FORCE to encode the speaker's surprise because it is encoded in the grammaticalized meaning of nante. Furthermore, unlike the intra-sentential nante, no degree property appears in the derivation, which accords with the fact that sentencefinal nante is not scalar.

3.2. Pragmatics. The semantic account in the previous section can at least explain why the exclamation with intra-sentential nante is necessarily scalar, while that with sentence-final nante is not. The difference is due to their different semantic calculations. However, it is not clear why one is challengable by no, and the other is not. This section aims to explain the different behaviors toward polarity particles (e.g., yes, no) between the two types of nante exclamations, claiming that their discourse effects are different: The exclamation with sentence-final nante aims to update the common ground, while that with intra-sentential nante does not.

3.2.1. BACKGROUND. I use the discourse model of Farkas \& Bruce (2010) to show the differences between the two nante exclamations. An example output discourse model after an assertion "Taro made delicious desserts" by A is given as Table 2.

\begin{tabular}{|l|l|c|}
\hline \multicolumn{1}{|c|}{ A } & \multicolumn{1}{c|}{ Table } & B \\
\hline $\mathrm{DC}_{A}: p$ & $\langle$ TMDD $; p\}\rangle$ & \\
\hline Common Ground: $s_{1}$ & Projected Set: $p s_{1}=\left\{s_{1} \cup\{p\}\right\}$ \\
\hline
\end{tabular}

Table 2. The output after an assertion, Taro made delicious desserts

There are four important components in the table. $\mathrm{DC}_{X}$ is the discourse commitment of speaker X. In Table 2, it is shown that A commits to the truth of proposition $p$, which is Taro made delicious desserts. Table is where a speaker puts an issue or the immediate Question under Discussion (QuD) (Roberts 1996, 2012). The pair of the syntactic form (here TMDD) and the semantic denotation is put here. The common ground is to be understood in the sense of Stalnaker (1978), which is the knowledge shared by discourse participants. Finally, the Projected Set shows possible future common ground. For example, in the case illustrated above, upon B's agreement, the proposition 'Taro made delicious desserts' is added to the common ground. In other words, the common ground is updated by making the union of the common ground at the utterance $\left(s_{1}\right)$ and a set of possible worlds in which $p$ is true.

3.2.2. Discourse EFFECTS OF EXClAmation With THE FinAL nante. Recall that the semantic denotation of the exclamation with the sentence-final nante is a proposition. Given that, I argue that this type of exclamation should be considered an assertion, albeit it is marked. Since it is a marked assertion, the discourse effect of the sentence-final nante can be built up 
by combining the basic discourse effects of declaratives and the extra effects tied to this specific assertion. In other words, the output table of the sentence-final nante exclamation is built upon what we have in Table 2 by adding an extra component. The results are shown in Table 3 .

\begin{tabular}{|l|c|c|}
\hline \multicolumn{1}{|c|}{ A } & Table & B \\
\hline $\mathrm{DC}_{A}$ : surprising' $(p)$ & $\langle$ TMDD $\{p\}\rangle$ & \\
\hline Common Ground: $s_{1}$ & Projected Set: $p s_{1}=\left\{s_{1} \cup\{p\}\right\}$ \\
\hline
\end{tabular}

Table 3. The output after the utterance of sentence-final nante

In the output discourse in Table 3, the addition is made to the discourse commitment of the speaker. As the special discourse effect of an assertion with nante, it is conveyed that the speaker is surprised at $p$. Meanwhile, the sentence radical part is added to the Table because this is an assertion. Consequently, the addressee (B, for example) can agree to it, and A and B can add $p$ to the common ground. Alternatively, B can challenge it by saying no and deny the fact that the desserts were made by Taro, stating rather that they were store-bought.

This analysis argues that exclamations with sentence-final nante are marked assertions and hence have special discourse effects. However, being a "marked" assertion itself is not special in Japanese. Japanese has many discourse particles such as yo, ne, no $(d a)$ that are used sentence-finally and provide extra information on context (cf. Northrup (2014) or Hirayama (2019), among others). For instance, no( $d a)$ signals that there is contextual evidence that suggests that the sentence radical is true. The analysis presented in this paper adds sentence-final and grammaticalized nante to the list of elements that can make assertions marked.

3.2.3. DisCOURSE EFFECTS OF EXCLAMATION WITH THE INTRA-SENTENTIAL nante. When an exclamation is made with intra-sentential nante, I claim that this exclamation is to be considered a bonafide exclamative, not an assertion. In other words, it is a different sentence type.

Sentence types are often distinguished by different syntactic forms in English, while Japanese uses particles or intonation. For instance, the most frequently used strategy to mark interrogatives is rising intonation. Alternatively, the question particle $k a$ can be used. However, in the case of exclamatives, it is possible to detect a special syntax reserved for exclamatives (Ono 2006). One notable aspect is the use of the focus marker no and the mood marker daroo, as shown in (15). Without it, the sentence is ungrammatical.

Taro-wa nante oisii dezaato-o tukuru*(no-daroo)!

T-TOP NANTE delicious dessert-ACC make FOC-MOOD

'What delicious desserts Taro makes!'

The syntactic property of this exclamation suggests that it has a different syntax from other sentence types, such as declaratives or interrogatives. Given that, it is safe to call this exclamation with a different sentence type a bonafide exclamative that hence has its own discourse effects.

The discourse effects of a bonafide exclamative in Japanese are as follows: It updates the discourse commitment of the speaker. They commit that they are surprised by the fact denoted by the sentence radical. Unlike declaratives, exclamatives do not put anything on the Table. 
As a result, the projected set remains the same because nothing is raised as an issue. ${ }^{5}$ The discourse effects are shown schematically in Table 4.

\begin{tabular}{|l|c|c|}
\hline \multicolumn{1}{|c|}{ A } & Table & B \\
\hline $\mathrm{DC}_{A}$ : surprising' $(p)$ & \multicolumn{3}{|c|}{} \\
\hline Common Ground: $s_{1}$ & Projected Set: $p s_{1}=\left\{s_{1}\right\}$ \\
\hline
\end{tabular}

Table 4. The output after the utterance of intrasentential nante

Polarity particles in languages are different in terms of the features they can represent when answering assertions or questions. While English no responses can realize [REVERSE] or [-] features (Roelofsen \& Farkas 2015), as shown in (16), Japanese polarity particles are known to be sensitive only to [AGREE/REVERSE] features (Pope 1972; Yabushita 1992), as shown in (17):

Polarity particles in English

A: John did not come.

B: No, he DID.

[No realizes REVERSE ]

B: No, he did not.

[No realizes - ]

(17) Polarity particles in Japanese

Taro did not come.

a. $\quad \checkmark$ Iya, John-wa kimasita.

No, John-TOP came

'No, John did come.'

b. *Iya, John-wa kimasendesita.

No, John-TOP did not come

'No, John did not come.'

Specifically, what is under discussion in this paper is no used to challenge the speaker, which is tied to the [REVERSE] feature, which is the only feature that Japanese no realizes. This feature crucially depends on what is on the Table because the feature shows that the answer agrees to or reverses the immediate QuD. When an exclamative is used, there is nothing on the Table, and this is why challenging the exclamation with the intra-sentential nante by saying no is infelicitous.

In sum, the most crucial difference between the two nante sentences is whether to put a proposition on the Table. A bonafide exclamative, in Japanese at least, does not update the future common ground but manifests the speaker's surprise toward the proposition denoted by the sentence radical. On the other hand, when nante is used in sentence-final position, it marks a special type of assertion and shares the basic discourse effects that other assertions have. This proposition is treated as an immediate QuD and is accessible by polarity particles. As a result, the addressee can challenge it, if necessary.

4. Conclusion and future directions. This paper has shown how two exclamations with nante in Japanese can be analyzed in terms of their different discourse effects. Their difference in

\footnotetext{
${ }^{5}$ It is possible to add the fact that the speaker was surprised to the common ground. However, it is doubtful whether an exclamative does this as its own discourse effects.
} 
scalarity is explained by the different semantic types attached to the two nantes, and I argue that one of them is grammaticalized so that it conveys the speaker's surprise. In contrast, the different behavior toward no is explained by different discourse effects, as their sentence types are different: One is a marked assertion, and the other is a bonafide exclamative. Unlike an assertion, an exclamative does not put an issue on the Table, which makes responding by saying no infelicitous.

This study explored two exclamative expressions involving nante, but they are not the only way to express surprise. One interesting example is shown in (18).

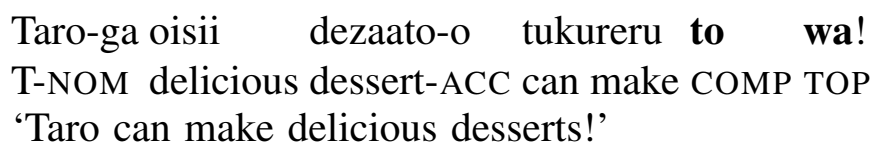

This example is similar to the exclamation with the sentence-final nante in terms of the form, scalarity, and behavior toward the polarity particle. One notable feature is that this involves the topic particle $w a$ at the end. Should this be treated as an instance of contrastive wa? If so, can we derive the discourse effect of (18) compositionally? These are fascinating open problems that need to be addressed.

In the example above, $w a$ is used sentence-finally. When it is used somewhere inside the sentence as contrastive $w a$, it also displays interesting behavior with exclamations. It has been pointed out that contrastive $w a$ is incompatible with bonafide exclamatives, as shown in (19).

(19) ??Taro-wa nante oisii dezaato-wa tukureru no-daroo!

T-TOP NANTE delicious dessert-WA can make FOC-MOOD

'What delicious desserts ${ }_{\mathrm{CT}}$ Taro can make!'

This is mysterious because contrastive $w a$ is compatible with various types of speech acts and exclamatives are exceptions for some unknown reasons (Tomioka 2009). However, contrastive wa can appear in a sentence-final nante exclamation, as shown in (20).
Taro-ga oisii dezaato-wa tukureru nante!
T-NOM delicious dessert-WA can make NANTE
'Taro can make delicious desserts ${ }_{\mathrm{CT}}$ !'

This is a welcome result for the analysis proposed in this paper because (20) is treated as an assertion, with which contrastive wa is compatible. By adding wa to the assertion with nante, the speaker can convey implications such that they expected Taro to be a terrible cook of appetizers or main dishes, but he made surprisingly good desserts; in addition, they were surprised at the fact that Taro made delicious desserts. It seems possible to obtain this implication compositionally by combining the discourse effects of nante discussed in this paper and those of contrastive wa argued in Hirayama (2019), but another study is needed to fully discuss the issues.

Finally, some discourse particles can appear with exclamations. For instance, the particle $n e$ can be used with a bonafide exclamative, as in (21).

Taro-wa nante oisii dezaato-o tukureru no-daroo ne!

T-TOP NANTE delicious dessert-ACC can make FOC-MOOD NE

'What delicious desserts Taro can make!' 
To the best of my knowledge, the literature on discourse particles has focused on the interaction between these particles and declaratives or interrogatives. Exploring interactions between discourse particles and exclamatives is also an interesting realm to investigate.

\section{References}

Chernilovskaya, Anna, Cleo Condoravdi \& Sven Lauer. 2012. On the discourse effects of $w h$ exclamatives. In Nathan Arnett \& Ryan Bennett (eds.), Proceedings of the 30th West Coast Conference on Formal Linguistics (WCCFL), 109-119. Somerville, MA: Cascadilla.

Farkas, Donka F. \& Kim B. Bruce. 2010. On reacting to assertions and polar questions. Journal of Semantics 27(1). 81-118. https://doi.org/10.1093/jos/ffp010.

Farkas, Donka F. \& Floris Roelofsen. 2017. Division of labor in the interpretation of declaratives and interrogatives. Journal of Semantics 34(2). 237-289. https://doi.org/10.1093/jos/ffw012.

Hirayama, Hitomi. 2019. Asking and answering questions: Discourse strategies in Japanese. Santa Cruz, CA: University of California dissertation.

Northrup, Oliver. 2014. Grounds for commitment. Santa Cruz, CA: University of California dissertation.

Ono, Hajime. 2006. An investigation of exclmatives in English and Japanese: Syntax and sentence processing. College Park, MD: University of Maryland dissertation.

Pope, Emily. 1972. Questions and answers in English: Cambridge, MA: MIT dissertation.

Rett, Jessica. 2011. Exclamatives, degrees and speech acts. Linguistics and Philosophy 34. 411-442. https://doi.org/10.1007/s10988-011-9103-8.

Roberts, Craige. 1996. Information structure in discourse: Towards an integrated formal theory of pragmatics. In Jae Hak Yoon \& Andreas Kathol (eds.), OSUWPL volume 49: Papers in semantics. Columbus, OH: The Ohio State University.

Roberts, Craige. 2012. Information structure in discourse: Towards an integrated formal theory of pragmatics. Semantics \& Pragmatics 5(6). 1-69. https://doi.org/10.3765/sp.5.6.

Roelofsen, Floris \& Donka F. Farkas. 2015. Polarity particle responses as a window onto the interpretation of questions and assertions. Language 91(2). 359-414. https://doi.org/10.1353/lan.2015.0017 .

Stalnaker, Robert. 1978. Assertion. In Peter Cole (ed.), Syntax and Semantics, vol. 9, 315-332. New York: Academic Press.

Tomioka, Satoshi. 2009. Contrastive topics operate on speech acts. In Malte Zimmermann \& Caroline Fèry (eds.), Information structure: Theoretical, typological, and experimental perspectives, 115-138. Oxford: Oxford University Press.

Yabushita, Katsuhiko. 1992. Why do Japanese hai and iie not behave like English yes and no all the way?: Consequences of the non-sentential operation of the Japanese negative morpheme nai. Kansas Working Papers in Linguistics 23(1). 59-73. 